\title{
ON THE CLASS OF $(\boldsymbol{A}, \boldsymbol{n})$-REAL POWER POSITIVE OPERATORS IN SEMI-HILBERTIAN SPACE
}

\section{ABDELKADER BENALI}

(Received 24 June 2019; Revision Accepted 20 August 2019)

\begin{abstract}
In this paper, the concept of the class of $n$-Real power positive operators on a hilbert space defined by Abdelkader Benali in [1] is generalized when an additional semi-inner product is considered. This new concept is described by means of oblique projections. For a Hilbert space operator $T \in B(H)$ is $(A, n)$-Real power positive operators for some positive operator $A$ and for some positive integer $n$ if

$$
T^{n}+T^{\sharp n} \geq_{A} 0, n=1,2, \ldots
$$

KEYWORDS: Real power, Semi-Hilbertian space, Semi-inner product, Positive operators. 2000 Mathematics Subject Classification: Primary 47B20. Secondary 47B99.

\section{INTRODUCTION}

A bounded linear operator $T$ on a complex Hilbert space is $n$-Real power positive operators if $T^{n}+T^{\sharp n} \geq$ 0 . The class of $(A, n)$-power positive operators was introduced and studied by Sidi Hamidou Jah see [16], from the definition, it is easily seen that this class contains power positive operators, in [12] the authors O.A. Mahmoud Sid Ahmed introduced the class $n-$

power quasi normal operators and study some properties of such class for different values of the parameter $n$. In [1] we introduce a new class of operators $T$ namely n-real power positive operator denoted by $[n \mathcal{R P}]$ satisfying $T^{n}+T^{* n} \geq 0$, for $n=$ $1,2,3, \ldots$

The purpose of this paper is to study the class of $(A, n)$-Real power positive operators in semi-hilbertian spaces, denoted by $[n \mathcal{R} \mathcal{P}]_{A}$.
\end{abstract}

\section{$2(A, n)$-REAL POWER POSITIVE OPERATORS}

Definition 2.1 For $n \in \mathbb{N}$, an operator $T \in \mathcal{L}(H)$ is said to be $(A, n)$-real power positive operator if $T^{n}+T^{\sharp n} \geq_{A} 0$ or equivalenty $A\left(T^{n}+T^{\# n}\right) \geq 0$.

Proposition 2.1 Let $T \in \mathcal{B}_{A}(\mathcal{H})$ and $n \in \mathbb{N}$ the following properties hold

(1) if $T \in[n \mathcal{R P}]_{A}$ then so $T^{\#}$.

(2) $T \in[n \mathcal{R} \mathcal{P}]_{A}$ if and only if $\operatorname{Re}\left\langle T^{n} x \mid x\right\rangle \geq_{A} 0 \quad \forall x \in \mathcal{H}$.

(3) If $T$ is invertible then $T \in[n \mathcal{R} \mathcal{P}]_{A}$ if and only if $T^{-1} \in[n \mathcal{R P}]_{A}$.

Abdelkader Benali, Faculty of the Exact sciences and Computer, Mathematics Department, Faculty of Science, Hassiba Benbouali, University of Chlef B.P. 151 Hay Essalem, Chlef 02000, Algeria. 
Proof. (1) Obvious from the definition 2.1.

(2) In fact, it is well known that

$$
\begin{aligned}
& T \in[n \mathcal{R P}]_{A} \Leftrightarrow T^{n}+T^{\# n} \geq_{A} 0 \Leftrightarrow\left\langle\left(T^{n}+T^{\# n}\right) x \mid x\right\rangle_{A} \geq 0 \quad \forall \quad x \in \mathcal{H} \\
& \Leftrightarrow\left\langle T^{n} x \mid x\right\rangle_{A}+\left\langle T^{* n} x \mid x\right\rangle_{A} \geq 0 \quad \forall x \in \mathcal{H} \\
& \Leftrightarrow\left\langle T^{n} x \mid x\right\rangle_{A}+\left\langle x \mid T^{n} x\right\rangle_{A} \geq 0 \quad \forall \quad x \in \mathcal{H} \\
& \Leftrightarrow\left\langle T^{n} x \mid x\right\rangle_{A}+\overline{\left\langle T^{n} x \mid x\right\rangle_{A}} \geq 0 \quad \forall \quad x \in \mathcal{H} \\
& \Leftrightarrow 2 \operatorname{Re}\left\langle T^{n} x \mid x\right\rangle_{A} \geq_{A} 0 .
\end{aligned}
$$

(3)Assume that $T$ is invertible and $T \in[n \mathcal{R} \mathcal{P}]_{A}$ we have $\operatorname{Re}\left\langle T^{n} x \mid x\right\rangle \geq_{A} 0 \quad \forall \quad x \in \mathcal{H}$. It follows that for all $x \in \mathcal{H}$,

$$
0 \leq \operatorname{Re}\left\langle T^{n} T^{-n} x \mid T^{-n} x\right\rangle_{A}=\operatorname{Re}\left\langle x \mid T^{-n} x\right\rangle_{A}=\operatorname{Re} \overline{\left\langle T^{-n} x \mid x\right\rangle_{A}}=\operatorname{Re}\left\langle T^{-n} x \mid x\right\rangle_{A} \text {. }
$$

Hence $T^{-1} \in[n \mathcal{R P}]_{A}$. The converse is obvious.

The following examples show that the two classes $[n \mathcal{R P}]_{A}$ and $[(n+1) \mathcal{R P}]_{A}$ are not the same.

Example 2.1 Let $T=\left(\begin{array}{ll}1 & 0 \\ 1 & 1\end{array}\right), A=\left(\begin{array}{ll}0 & -1 \\ 1 & 0\end{array}\right) \in \mathcal{B}\left(\mathbb{C}^{2}\right)$. A simple computation shows that

For all $(u, v) \in \mathbb{C}^{2}$ we have

$$
T^{\#}=\left(\begin{array}{ll}
1 & 0 \\
-1 & 1
\end{array}\right) \text { and } T^{n}+T^{\sharp n}=n\left(\begin{array}{ll}
1 & 0 \\
0 & 1
\end{array}\right) \text {. }
$$

$$
\left\langle\left(T^{n}+T^{\sharp n}\right)\left(\begin{array}{l}
u \\
v
\end{array}\right)\left|\left(\begin{array}{l}
u \\
v
\end{array}\right)\right|_{A}=0 \geq_{A} 0 .\right.
$$

So $T \in[n \mathcal{R P}]_{A}$.

Example 2.2 Let $T=\left(\begin{array}{lll}1 & 1 & 1 \\ 0 & 0 & 0 \\ 0 & 0 & 0\end{array}\right), A=\left(\begin{array}{lll}1 & 0 & 0 \\ 0 & 1 & 0 \\ 0 & 0 & 1\end{array}\right) \in \mathcal{B}\left(\mathbb{C}^{3}\right)$. It is easy to see that $T \notin[n \mathcal{R} \mathcal{P}]_{A}$ for all $n=$ $1,2, \ldots$

Example 2.3 Let $T=\left(\begin{array}{ll}1 & 1 \\ -1 & 1\end{array}\right), A=\left(\begin{array}{ll}1 & -1 \\ 1 & 1\end{array}\right) \in \mathcal{B}\left(\mathbb{C}^{2}\right)$. A simple computation shows that

$$
T^{\sharp}=\left(\begin{array}{cc}
1 & -1 \\
1 & 1
\end{array}\right), T^{2}+T^{\sharp 2}=\left(\begin{array}{ll}
0 & 0 \\
0 & 0
\end{array}\right) \text { and } T^{3}+T^{\sharp 3}=4\left(\begin{array}{cc}
-1 & 0 \\
0 & -1
\end{array}\right) \text {. }
$$

For all $(u, v) \in \mathbb{C}^{2}$ we have

$$
\left\langle\left(T^{2}+T^{\sharp 2}\right)\left(\begin{array}{l}
u \\
v
\end{array}\right)\left|\left(\begin{array}{l}
u \\
v
\end{array}\right)\right|_{A}=0 \geq_{A} 0 .\right.
$$

Hence $T \in[2 \mathcal{R P}]_{A}$.

On the other hand

$$
\left\langle\left(T^{3}+T^{\sharp 3}\right)\left(\begin{array}{l}
u \\
v
\end{array}\right)\left|\left(\begin{array}{l}
u \\
v
\end{array}\right)\right|_{A}=-u^{2}-v^{2} \leq_{A} 0 .\right.
$$

So $T \notin[3 \mathcal{R P}]_{A}$. 
Proposition 2.2 If $S, T \in B_{A}(H)$ are unitarily equivalent and if $T$ is $(A-n)$-real power positive operators then so is $S$.

Proof. Let $\mathrm{T}$ be an (A-n)-real power positive operator and $\mathrm{S}$ be unitary equivalent of $\mathrm{T}$. Then there exists unitary operator $U$ such that $S=U T U^{\sharp}$ so $S^{n}=U T^{n} U^{\#}$

We have

$$
\begin{aligned}
T \in[n \mathcal{R P}]_{A} & \Leftrightarrow T^{n}+T^{\sharp n} \geq_{A} 0 \Leftrightarrow\left(T^{n}+T^{\# n}\right) U^{\sharp} \geq_{A} 0 \\
& \Leftrightarrow U\left(T^{n}+T^{\# n}\right) U^{\sharp} \geq_{A} 0 \\
& \Leftrightarrow U T^{n} U^{\sharp}+U T^{\# n} U^{\sharp} \geq_{A} 0 \\
\Leftrightarrow S^{n} & +S^{\sharp n} \geq_{A} 0 \\
\Leftrightarrow S & \in[n \mathcal{R P}]_{A}
\end{aligned}
$$

Theorem 2.1 Let $T, S \in[n \mathcal{R P}]_{A}$ such that $T^{k} S=-S^{k} T$ for $k=1,2, \ldots, n-1$ with $n \geq 2$, then $T+S \in[n \mathcal{R P}]_{A}$.

Proof. From the hypothesis it is clear that $(T+S)^{n}=T^{n}+S^{n}$ and so that

$$
(T+S)^{n}+\left(T^{\#}+S^{\sharp}\right)^{n}=\underbrace{T^{n}+T^{\# n}}_{\geq_{A} 0}+\underbrace{S^{n}+S^{\# n}}_{\geq_{A} 0} \geq_{A} 0 .
$$

Lemma 2.1 Let $T, S \in \mathcal{B}(\mathcal{H})$ such that $T \geq_{A} S$ and let $R \in \mathcal{B}_{A}(\mathcal{H})$. Then the following properties hold

(1) $R^{\sharp} T R \geq_{A} R^{\sharp} S R$.

(2) $R T R^{\sharp} \geq_{A} R S R^{\#}$.

(3) If $R$ is $A$-selfadjoint then $R T R \geq_{A} R S R$.

Proposition 2.3 If $T \in[n \mathcal{R P}]_{A}$ is such that $T^{\sharp} T^{2}=T^{2} T^{\#}$ then $T^{\sharp} T^{2} \in[n \mathcal{R} \mathcal{P}]_{A}$.

Proof. Since $T \in[n \mathcal{R P}]_{A}$ we have by Lemma 3.1 that

$$
\begin{aligned}
T^{n}+T^{\sharp n} \geq_{A} 0 & \Rightarrow T^{\sharp n} T^{n} T^{n}+T^{\sharp 2 n} T^{n} \geq_{A} 0 \\
& \Rightarrow\left(T^{\sharp} T^{2}\right)^{n}+\left(T^{\sharp 2} T\right)^{n} \geq_{A} 0\left(\text { since } \quad T^{\sharp} T^{2}=T^{2} T^{\sharp}\right) \\
& \Rightarrow\left(T^{\sharp} T^{2}\right)^{n}+\left(T^{\sharp} T^{2}\right)^{\sharp n} \geq_{A} 0 .
\end{aligned}
$$

Hence $T^{\sharp} T^{2} \in[n \mathcal{R P}]_{A}$ as required.

Proposition 2.4 Let $T \in \mathcal{B}_{A}(\mathcal{H})$. Consider $F=T^{n-1}+T^{\#}$ and $G=T^{n-1}-T^{\#}$ for $n \in \mathbb{N}$. If $T$ is normal then the following equivalence holds

$T \in[n \mathcal{R P}]_{A} \quad$ if and only if $\quad F F^{\#} \geq_{A} G G^{\#}$.

Proof. Since $T$ is normal we have

$$
\begin{aligned}
F F^{\sharp}-G G^{\#} & =\left(T^{n-1}+T^{\#}\right)\left(T^{\sharp n-1}+T\right)-\left(T^{n-1}-T^{\#}\right)\left(T^{\sharp n-1}-T\right) \\
& =T^{n}+T^{\# n} .
\end{aligned}
$$

From which it follows that

$$
T \in[n \mathcal{R P}]_{A} \Leftrightarrow T^{n}+T^{\sharp n} \geq_{A} 0 \Leftrightarrow F F^{\#}-G G^{\#} \geq_{A} 0 .
$$

Proposition 2.5 Let $T \in \mathcal{B}_{A}(\mathcal{H})$.

(1) If $T$ is almost subprojection, then

$$
T \in[2 \mathcal{R P}]_{A} \text { if and only if } T \in[4 \mathcal{R P}]_{A} .
$$

(2) If $T$ is idempotent, then

$$
T \in[\mathcal{R P}]_{A} \quad \text { if and only if } \quad T \in[n \mathcal{R P}]_{A} .
$$

Proof. (1) $\mathrm{T}$ is almost subprojection, $\mathrm{T}^{4}=\mathrm{T}^{\sharp 2}$ for all $\mathrm{x} \in \mathcal{H}$ (see [4]) we have

So

$$
\operatorname{Re}\left\langle T^{2} x \mid x\right\rangle_{A}=\operatorname{Re}\left\langle T^{\# 4} x \mid x\right\rangle_{A}=\operatorname{Re}\left\langle x \mid T^{4} x\right\rangle_{A}=\operatorname{Re} \overline{\left\langle T^{4} x \mid x\right\rangle}=\operatorname{Re}\left\langle T^{4} x \mid x\right\rangle_{A}
$$

$$
T \in[2 \mathcal{R P}]_{A} \geq 0 \Leftrightarrow T \in[4 \mathcal{R P}]_{A} \geq 0 .
$$

(2) Since $T$ is idempotent we have $T=T^{2}=\ldots=T^{n}$ and so that

$$
T^{n}+T^{\sharp n}=T+T^{\#} \text {. }
$$

Hence the desired result. 
The following examples show that an operator $T \in[n \mathcal{R P}]_{A}$ need not be almost subprojection and vice versa.

Example 2.4 Let $\square=\left(\begin{array}{ll}1 & 0 \\ 0 & 2\end{array}\right) \quad \square \square \square \square=\left(\begin{array}{ll}1 & 0 \\ 0 & 1\end{array}\right)$ be an operator acting in two- dimensional complex Hilbert space. then $\square \in[\square \square \square]_{\square}$ for all $\square \in \square$. Now, by direct calculation $\square^{4}=\left(\begin{array}{ll}1 & 0 \\ 0 & 16\end{array}\right) \neq\left(\begin{array}{ll}1 & 0 \\ 0 & 4\end{array}\right)=$ $\square 2$

Theorem 2.2 Let $\square, \square \in \square_{\square}(\square)$ such that $\square \square=\square \square=\square+\square$. If $\square$ and $\square$ are in $[\square \square \square]_{\square}$ for $\square=1,2, \ldots, \square$, then $\square \square \in[\square \square \square]_{\square}$.

Proof. For $\square=1$. Assume that $\square$ and $\square$ are in $[\square \square]_{\square}$. We have

and so $\square \square \in[\square[\square]]_{\square}$.

For $\square=2$. Assume that $\square$ and $\square$ are in $[\square \square \square]_{\square}$ for $\square=1,2$. We have

$$
\begin{aligned}
(\square \square)^{2}+(\square \square)^{\sharp 2} & =(\square+\square)^{2}+\left(\square^{\sharp}+\square^{\sharp}\right)^{2} \\
& =\square^{2}+2 \square \square+\square^{2}+\square \sharp 2+2 \square^{\sharp} \square^{\sharp}+\square \sharp 2 \\
& =\underbrace{\square^{2}+\square \square^{\sharp 2}}_{\geq \square}+2 \underbrace{\left(\square \square+(\square \square)^{\#}\right)}_{\geq \square}+\underbrace{\square^{2}+\square^{\sharp 2}}_{\geq 0}
\end{aligned}
$$

and so $\square \square \in[2 \square \square]_{\square}$. Assume that this result is true for $\square-1$ and we prove it for $\square$. Let $\square$ and $\square$ be in $[\square \square \square]_{\square}$ for $\square=1,2, \ldots, \square$. Since $\square \square=\square \square=\square+\square$ we have $(\square \square)^{\square}+(\square \square)^{* \square}=(\square+\square)^{\square}+\left(\square+\square{ }^{\sharp}\right)$

$$
=\square^{\square}+\square^{\# \square}+\sum_{1 \leq \square \leq \square-1}\left(\begin{array}{l}
\square \\
\square
\end{array}\right)\left(\square^{\square} \square^{\square-\square}+\square^{\# \square} \square^{\# \square-\square}\right)+\square^{\square}+\square^{\# !} \text {. }
$$

It suffice to prove under the assumptions that $\square^{\square} \square^{\square-\square}+\square^{\sharp \square} \square \square-\square \geq \geq_{\square} 0$,for $\square=1,2, \ldots, \square-1$.

For $\square=1$ we have

For $\square=2$ we have

$$
\begin{aligned}
& \square \square^{\square-1}+\square^{\#} \square^{\# \square-1}=\square \square \square^{\square-2}+\square^{\#} \square^{\#} \square^{\# \square-2} \\
& =(\square+\square) \square^{\square-2}+\left(\square^{\#}+\square^{\#}\right) \square^{\sharp \square-2} \\
& =\square \square^{\square-2}+\square^{\#} \square^{\# \square-2}+\underbrace{\square^{\square-1}+\square^{\sharp \square-1}}_{\geq 0^{-}} \\
& =\square \square \square^{\square-3}+\square^{\#} \square^{\#} \square \# \square-3+\underbrace{\square^{\square-1}+\square \# \square-1}_{\geq \square 0} \\
& =\square \square^{\square-3}+\square^{\#} \square^{\# \square-3}+\underbrace{\square^{\square-2}+\square^{\sharp \square-2}}_{\geq \square}+\underbrace{\square^{\square-1}+\square \sharp \square-1}_{\geq \square} \\
& =\cdots \quad \cdots \quad \cdots \\
& =\sum_{1 \leq \square \leq \square-1}(\underbrace{\square^{\square}+\square \sharp \square}_{\geq \square 0}+\underbrace{\square^{\square}+\square \# \square}_{\geq \square 0}) .
\end{aligned}
$$

$$
\begin{aligned}
& \square^{2} \square^{\square-2}+\square^{\sharp 2} \square^{\# \square-2}=\square \square \square \square^{\square-3}+\square^{\#} \square^{\#} \square^{\#} \square^{\# \square-3} \\
& =\square^{2} \square^{\square-3}+\square \square^{\square-2}+\square^{\# 2} \square^{* \square-3}+\square^{\#} \square^{\# \square-2} \\
& =\square^{2} \square^{\square-4}+\square \square^{\square-3}+\square \square^{\square-2}+\square^{\sharp 2} \square^{\sharp \square-4}+\square^{\#} \square^{\# \square-3}+\square^{\#} \square^{\sharp \square-2} \\
& =\square^{2} \square^{\square-5}+\square \square^{\square-4}+\square \square^{\square-3}+\square \square^{\square-2} \\
& +\square^{\# 2} \square \# \square-5+\square^{\#} \square^{\# \square-4}+\square^{\#} \square^{\# \square-3}+\square^{\#} \square \# \square-2 \\
& =\cdots
\end{aligned}
$$

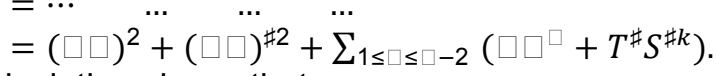

A simple calculation shows that

$$
T S^{k}+T^{\sharp} S^{\sharp k}=T+T^{\sharp}+\sum_{1 \leq j \leq k}\left(S^{j}+S^{\sharp j}\right) \text {. }
$$

We deduce that $T^{2} S^{n-2}+T^{\sharp 2} S^{\sharp n-2}$

$$
=(T S)^{2}+(T S)^{\sharp 2}+\sum_{1 \leq k \leq n-2}\left(T+T^{\sharp}+\sum_{1 \leq j \leq k}\left(S^{j}+S^{\# j}\right)\right) \geq_{A} 0 .
$$


Same way for $p=3, \ldots, n-1$. Hence $(T S)^{n}+(T S)^{\sharp n} \geq_{A} 0$ as required.

Example 2.5 Let $S=T=\left(\begin{array}{ccc}1 & 1 & 1 \\ 1 & 1 & 1 \\ 1 & 1 & 1\end{array}\right), A=\left(\begin{array}{lll}1 & 0 & 0 \\ 0 & 1 & 0 \\ 0 & 0 & 1\end{array}\right)$. it is easy to see that $T \in[k \mathcal{R P}]_{A}$ for $k=1,2, \ldots, n$ and $T S \in[n \mathcal{R P}]_{A}$.

The following example shows that Theorem 2.3 is not necessarily true if $\square \square \neq \square+\square$.

Example 2.6 Let $\square=\left(\begin{array}{ll}1 & 1 \\ 1 & 1\end{array}\right), \square=\left(\begin{array}{ll}1 & 0 \\ 0 & 1\end{array}\right)$ and $\square=\left(\begin{array}{ll}1 & 1 \\ -1 & 1\end{array}\right)$. We have $\square$ and $\square$ in $[\mathcal{R} \square]_{\square}, \square \square \neq \square+\square$ and $\notin[2 \mathcal{R} \square]_{\square}$.

Proposition 2.6 Let $\square, \square \in \mathcal{B}_{\square}(\mathcal{H})$. If $\square \in[\square \mathcal{R} \square]_{\square}$ and $\square$ is unitary equivalent to $\square$, then $\square \in[\square \mathcal{R} \square]_{\square}$.

Proof. By assumption, there is a unitary equivalent operator $\mathrm{U} \in \mathcal{B}_{\mathrm{A}}(\mathcal{H})$ such that $\mathrm{S}=\mathrm{U}^{-1} \mathrm{TU}$, which implies that

$$
\square^{\#}=\square^{\#} \square^{\#}\left(\square^{-1}\right)^{\#}=\square^{\#} \square^{\#}\left(\square^{\#}\right)^{-1} \text {. }
$$

Thus we have

$$
\begin{aligned}
& \square^{\square}=\square^{-1} \square \square \square^{-1} \square \square \ldots \square^{-1} \square \square=\square^{-1} \square^{\square} \square \\
& -\square^{\# \square}=-\square^{\#} \square^{\#}\left(\square^{\#}\right)^{-1} \ldots \square^{\#} \square^{\#}\left(\square^{\#}\right)^{-1} \\
& =-\square^{\#} \square^{\#}\left(\square^{\#}\right)^{-1} .
\end{aligned}
$$

Since $\square$ is A-unitary and using the fact that $\square^{\square} \geq \square-\square^{\# \square}$ we conclude that

$$
\square^{-1} \square^{\square} \square \geq \square-U^{\#} \square^{\# \square}\left(\square^{\#}\right)^{-1} \text {. }
$$

Thus $\square^{\square} \geq \square-\square$.

Theorem 2.3 Let $\square \in \square_{\square}(\square)$ the following properties hold

(1) If $\square \square$ is unitary equivalent to $\square \sharp \square-1$ then

$\square \in[\square \square \square]_{\square} \Leftrightarrow \square \in[(\square-1) \square \square]_{\square}, \square=2,3, \ldots$

(2) If $\square \square$ is unitary equivalent to $\square \square-1$ for $\square=1 \ldots \ldots$ then

$\square \in[\square \square \square]_{\square} \Leftrightarrow \square \in[\square \square]_{\square}, \square=2,3, \ldots$.

Proof. (1) From the hypothesis there exists an operator $\mathrm{U} \in \mathcal{B}_{\mathrm{A}}(\mathcal{H}): \mathrm{U}^{\sharp} \mathrm{U}=\mathrm{UU}^{\sharp}=\mathrm{P}_{\overline{\mathcal{R}}(\mathrm{A})}$ such that $\mathrm{T}^{\mathrm{n}}=\square \square^{\sharp} \square-1 \square$.

Firstly, assume that $\square \in[\square \square \square]_{\square}$, it follows that

$$
\square^{\square}+\square^{\sharp} \geq_{\square} 0 \Longrightarrow \square^{\#} \square^{\# \square-1} \square+\square^{\#} \square^{\square-1} \square \geq_{\square} 0 \Rightarrow \square^{\#}\left(\square^{\square-1}+\square^{\# \square-1}\right) \square \geq_{\square} 0 .
$$

By Lemma 2.1, we deduce that $\square^{\square-1}+\square^{\# \square-1} \geq \quad 0$ and hence $\square \in[(\square-1) \square \square]$.

Conversely, assume that $\square \in[(\square-1) \square \square]$. We have by Lemma 2.1

Hence $\square \in[\square \square \square]_{\square}$.

$$
\square^{\square-1}+\square^{\sharp \square-1} \geq_{\square} 0 \Rightarrow \square^{\sharp}\left(\square^{\square-1}+\square \# \square-1\right) \square \geq_{\square} 0 \Rightarrow \square^{\square}+\square^{\sharp \square} \geq_{\square} 0 .
$$

(2) From the hypothesis we have

$$
\square=\square \square^{\square} \square \square-1 \square \square \quad \square \square \square \quad \square=1,2, \ldots, \square .
$$

If we assume that $\square \in[\square \square \square]_{\square}$ we have from (1) that $\square \in[(\square-1) \square \square]_{\square}$. Repeating the process with $\square \in[(\square-$ 1) $\square \square]_{\square}$ we obtain that $\square \in[(\square-2) \square \square]$. Hence the following implications hold

$$
\square \in[\square \square \square]_{\square} \Rightarrow \square \in[(\square-1) \square \square]_{\square} \Rightarrow \square \in[(\square-2) \square \square]_{\square} \Rightarrow \ldots \square \in[2 \square \square]_{\square} \Rightarrow \square \in[\square \square]_{\square} .
$$

Conversely, assume that $\square \in[\square \square]$. By Lemma 2.1 we obtain

Also

$$
\square^{2}+\square^{\sharp 2}=\square_{2}^{\#}\left(\square+\square \# \square_{2} \geq_{\square} 0 \Rightarrow \square \in[2 \square \square]_{\square}\right. \text {. }
$$

$$
\square^{3}+\square^{\sharp 3}=\square_{3}^{\sharp}\left(\square^{2}+\square^{\sharp 2}\right) \square_{3} \geq_{\square} 0 \Rightarrow \square \in[3 \square \square]_{\square} .
$$


Repeating the process we obtain

This completes the proof.

$$
+\square^{\sharp \square}=\square^{\#}\left(\square^{\square-1}+\square \square^{\#-1}\right) \square_{\square} \geq_{\square} 0 \Rightarrow \square \in[\square \square \square]_{\square} \text {. }
$$

Proposition 2.7 If $\square \in[\square \square \square]_{\square}$ is such that $\square^{\#} \square^{2}=\square^{2} \square^{\#}$ then $\square^{\#} \square^{2} \in[\square \square \square]_{\square}$.

Proof. Since $\mathrm{T} \in[\mathrm{n} \mathcal{R \mathcal { P }}]_{\mathrm{A}}$ we have by Lemma 2.1 that

Hence $\square^{\#} \square^{2} \in[\square \square \square]_{\square}$ as required.

$$
\begin{aligned}
& \square^{\square}+\square^{\#} \geq_{\square} 0 \Rightarrow \square \# \square^{\square} \square^{\square}+\square^{\# 2 \square} \square^{\square} \geq_{\square} 0 \\
& \Rightarrow\left(\square^{\#} \square^{2}\right)^{\square}+\left(\square^{\# 2} \square\right)^{\square} \geq 0\left(\square \square \square \square \square \quad \square \square^{2}=\square^{2} \square^{\#}\right) \\
& \Rightarrow\left(\square^{\#} \square^{2}\right)^{\square}+\left(\square^{\#} \square^{2}\right)^{\# \square} \geq_{\square} 0 .
\end{aligned}
$$

\section{REFERENCES}

A.Benali, On the class of $\square$-Real Power Positive Operators On A Hilbert Space. Functional Analysis, Approximation and Computation, 10 (2) 2018, 23-31.

A.Aluthge, On $\square$-hyponormal Operators for $0<\square<1$, Integral Equations Operators Theory , 13. 1990, 307-315.

A.Benali and Ould Ahmed Mahmoud Sid Ahmed. $(\square, \square)$ - $\square$-Normal Operators In Semi-Hilbertian Spaces. Afrika Matematika, 2019, pp. 10129405, doi:10.1007/s13370-019-00690-3.

A. Brown, On a class of operators, Proc. Amer. Math. Soc, 4 1953, 723-728.

A. A.S. Jibril, On $\square$-Power Normal Operators.The Journal for Science and Engenering . Volume 33, Number 2A. 2008 247-251.

A. A.S. Jibril, On 2-Normal Operators Dirasat, Natural and Engineering Sciences. 2(23), 1996, 190195.

A. A. S, Jibril, On subprojection sperators, International Mathematical Journal, 4(3), 2003, pp. 229-238.

Cherifa Chellali and A.Benali. Class of $(\square, \square)$-powerhyponormal operators in semi-hilbertian space accepted, 2019 in the journal: Functional Analysis, Approximation and Computation.

M.Guesba and M.Nadir, On n-power-hyponormal operators Global Journal of pure and Applied Mathematics ISSN 0973-1768 Volume 12, Number 1. 2016, pp. 473-479.
M.Guesba and M.Nadir, On operators for wich $\square^{2} \geq-\square^{* 2}$. The Australian Journal of Mathematical Analysis and Applications. Volume 13, Issue 1, pp. 1-5, 2016.

Ould Ahmed Mahmoud Sid Ahmed, On the class of npower quasi-normal operators on Hilbert spaces, Bull. Math. Anal. Appl, 3(2), 2011, 213-228.

Ould Ahmed Mahmoud Sid Ahmed, On Some Normality-Like Properties and Bishops Property $(\square)$ for a Class of Operators on Hilbert Spaces, International Journal of Mathematics and Mathematical Sciences, 2012. doi:10.1155/2012/975745.

Ould Ahmed Mahmoud Sid Ahmed and Abdelkader Benali, Hyponormal And $\square$-Quasi-hyponormal Operators On Semi-Hilbertian Spaces, The Australian Journal of Mathematical Analysis and $\quad 2012$. doi:10.1155/2012/975745.

Riyandh R. Al-Mosawi and Hadeel A. Hassan, A Note on Normal and n-Normal Operators, journal of university of Thi-Qar, volume 9, Issue 1, 2014, $1-4$.

Sidi Hamidou Jah, Class Of ( $\square, \square)$-Power-Quasihyponormal Operators In Semi-Hilbertian Spaces, International Journal of Pure and Applied Mathematics . Volume 93 No.1 2014, 61-83.

S.Panayappan and N.Sivamani, On n-binormal operators Gen. Math. Notes, Volume 10, No. 2, June 2012, PP. 1-8. 